九州大学学術情報リポジトリ

Kyushu University Institutional Repository

\title{
Development of A Measuring Method for Acousto- ULtrasonic Transmission in Thickness Direction of Particleboard
}

Lin, Han Chien

Laboratory of Wood Material Technology, Department of Forest Products, Graduate school of Bioresource and Bioenvironmental Science, Kyushu University

Matsumoto, Hiroshi

Ishikawa Wood Center, Wood Engineering Section, Ishikawa Forest Research Institute

Fujimoto, Yoshiyasu

Laboratory of Wood Materical Technology, Division of Biomaterial Science, Department of Forest and Forest Products Science, Faculty of Agriculture, Kyushu University

Murase, Yasuhide

Laboratory of Wood Materical Technology, Division of Biomaterial Science, Department of Forest and Forest Products Science, Faculty of Agriculture, Kyushu University

https://doi.org/10.5109/24405

出版情報: 九州大学大学院農学研究院紀要. 45 (2)，pp.541-556，2001-02-28. Kyushu University バージョン：

権利関係: 


\title{
Development of A Measuring Method for Acousto-Ultrasonic Transmission in Thickness Direction of Particleboard
}

\author{
Han Chien LIN*, Hiroshi Matsumoto**, Yoshiyasu Fujimoto \\ and Yasuhide Murase ${ }^{* * *}$

\begin{abstract}
Laboratory of Wood Material Technology, Division of Biomaterial Science, Department of Forest and Forest Products Science, Faculty of Agriculture, Kyushu University, Fukuoka 812-8581, Japan
\end{abstract}

(Received October 30, 2000 and accepted November 10, 2000)

\begin{abstract}
In ultrasonic wave transmission test, the measurement conditions concerned with the thickness of the particleboard, such as the dimensions and setup of the test specimen, the mounted position of the sensors and the fixing pressure of the sensors, had a significant influence on the measurement of the ultrasonic velocity and the maximum amplitude of transmitted ultrasonic wave. These parameters were examined in this paper.

No significant influence on the velocity measurements was found within the range of the conditions used in this study. It was confirmed that there was no remarkable attention to the acousto-ultrasonic measurement. However, the dimensions and setup of test specimen influenced the maximum amplitude, which involves the attenuation of the ultrasonic wave. It is suggested that the dimensions and setup of test specimen must be unified on the measurement of maximum amplitude using acousto-ultrasonic technique. The results indicated that the maximum amplitude was also influenced significantly by deviations in the horizontal direction of both sensors and the fixing pressure of the sensors to the surface of specimen. In order to solve these problems, an auxiliary apparatus, the built-in holders with a vice, was designed. Accurate and steady measurement values were obtained easily using this auxiliary apparatus for evaluating the ultrasonic wave transmission through particleboard thickness.
\end{abstract}

\section{INTRODUCTION}

The behavior of acoustic emission (AE) generation is profoundly related to the development of minute fracture in a material. It is one of the effective methods for determining the relationships between the mechanical properties and internal structure of wood based materials. In order to evaluate the relationships between the internal bond (IB) strength and the internal structures of particleboard (PB), the behavior of $\mathrm{AE}$ generation during tensile tests perpendicular to the plane was investigated by Fujimoto et al. As the result, basic information on the fracture mechanism in IB tests of PB was obtained (Y. Fujimoto et al., 1997). However, the AE signals detected in the IB tests were not the real $\mathrm{AE}$ signals generated at the fracture source (point). That is, they were the signals transmitted through the internal parts of material and then detected by the $\mathrm{AE}$

\footnotetext{
* Laboratory of Wood Material Technology, Department of Forest Products, Graduate school of Bioresource and Bioenvironmental Science, Kyushu University

** Ishikawa Wood Center, Wood Engineering Section, Ishikawa Forest Research Institute, Ishikawa 920-2306, Japan

*** Corresponding author (E-mail: ymurase@agr.kyushu-u.ac.jp)
} 
sensor mounted on the surface of the test specimen. Therefore, it is necessary to understand the characteristics of $\mathrm{AE}$ transmissions in the internal portions of $\mathrm{PB}$. The $\mathrm{AE}$ signals especially detected in IB tests are influenced by the moisture content (MC) and the internal structure of material for sheet products, such as particleboard.

Furthermore, in order to investigate the characteristics of $\mathrm{AE}$ transmissions during $\mathrm{IB}$ tests, it is necessary to destroy the test specimen, as $\mathrm{AE}$ are elastic waves that appeared when a material is destroyed. In this case, many test specimens must be prepared and there is also a problem of the reappearance. Therefore, so-called the acousto-ultrasonic (AU) measuring techniques are used. In other words, the ultrasonic wave, instead of the $\mathrm{AE}$ generation, is transmitted into a material (PB). And the difference in the shape of the ultrasonic wave before and after transmission is examined.

In the above-mentioned $\mathrm{AU}$ measurement techniques, the experimental measuring conditions, such as the dimension and form of the test specimen, the setting pattern, the mounted position and the fixing pressure of the sensors, may influence the measurement results. The objective of this research was to examine the influences of the experimental conditions and develop an optimized methodology in order to analyze the behavior of the ultrasonic wave transmission in the PB thickness direction using the ultrasonic pulse-transmission method.

\section{MATERIALS AND METHODS}

A commercial three-layer $\mathrm{PB}$, made with urea-formaldehyde resin (UMF type) adhesive, was used as specimens in this experiment. The basic properties of this $\mathrm{PB}$ are shown in Table 1. All specimens were cut into sizes required for each experiment and conditioned to equilibrium at $20^{\circ} \mathrm{C}$ and $65 \%$ relative humidity for about two months. The moisture content ranged from 8 to $10 \%$.

A diagram of the $\mathrm{AU}$ measuring system used in this study is shown in Fig. 1. The acoustic emission sensors, the wide range type (NF CORPORATION AE-900S-WB) and $12 \mathrm{~mm}$ in diameter, were used as transmitting and receiving transducers. They were mounted on the opposite face of a test specimen with wax in order to produce a stable adherence between the AE sensor and specimen. The pulsed ultrasonic wave from the

Table 1. The physical and mechanical properties of the commercial particleboard used in this experiment.

\begin{tabular}{lc}
\hline \multicolumn{1}{c}{ Properties } & Commercial particleboard \\
\hline Thickness $(\mathrm{mm})$ & $20.30(0.42)$ \\
Moisture content $(\%)$ & $8.8(0.1)$ \\
Density $\left(\mathrm{g} / \mathrm{cm}^{3}\right)$ & $0.74(0.03)$ \\
Internal bond strength $\left(\mathrm{kgf}^{\prime} / \mathrm{cm}^{2}\right)$ & $7.16(0.65)$ \\
Modulus of rupture $\left(\mathrm{kgf} / \mathrm{cm}^{2}\right)$ & $173.6(6.6)$ \\
Modulus of elasticity $\left(\times 10^{3} \mathrm{kgf} / \mathrm{cm}^{2}\right)$ & $27.21(0.97)$ \\
Remarks & 3 layers \\
& UMF \\
\hline
\end{tabular}

UMF: Urea-melamine formaldehyde resin adhesive

Values in parentheses are the standard deviations 


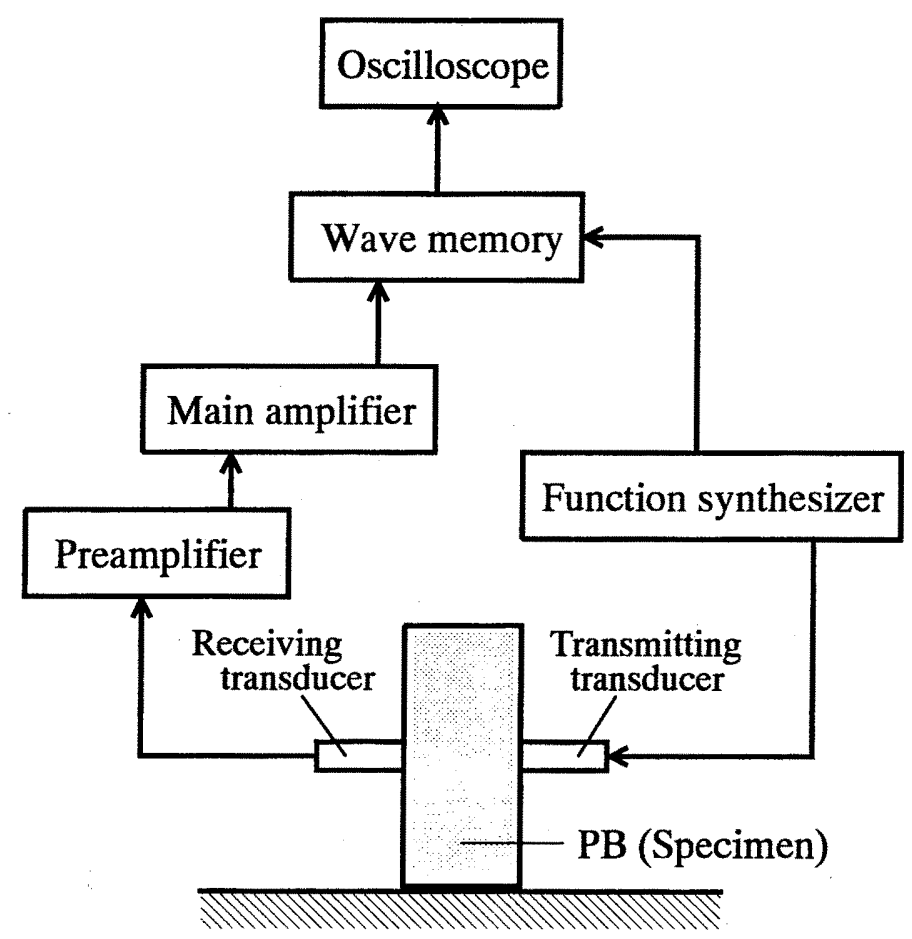

Fig. 1. A schematic diagram of the measuring system.

function synthesizer (NF CORPORATION 1915) was set with a frequency of $200 \mathrm{kHz}$. The pulsed ultrasonic wave was transmitted through the thickness direction of $\mathrm{PB}$ specimen. The transmitted ultrasonic wave was detected by the receiving transducer at the opposite side of specimen. Detected transmitted signals were amplified $20 \mathrm{~dB}$ and then $40 \mathrm{~dB}$ using a main amplifier (NF CORPORATION AE-912 and AE-922). The transmitted ultrasonic wave and the pulsed ultrasonic wave were recorded in wave memory (NF CORPORATION WM-852) at the same time. The transit time was obtained using a dual channel oscilloscope (ONO Sokki CF-910), which based upon the difference in time of occurrence from both signal waves. On the other hand, the maximum amplitude (V) was determined as the highest point of the transmitted ultrasonic wave. The velocity of the transmitted ultrasonic wave through the specimen thickness was determined from the following equation:

$$
\nu=l / t
$$

where $\nu$ is ultrasonic velocity $(\mathrm{m} / \mathrm{s}), l(\mathrm{~m})$ is the distance between two transducers, and $t$ is transit time (sec). 


\section{RESULTS AND DISCUSSION}

It is necessary to detect the background noise in advance of the experiment because it will influence with detecting the ultrasonic wave in the material. The background noise was monitored using the wave memory connected to an oscilloscope. The average value of the background noise detected without specimen was about $25 \mathrm{mV}$. A threshold level was decided at $30 \mathrm{mV}$ for the beginning point of the received transmitted ultrasonic wave.

In order to obtain a standard value for evaluating the attenuation of the transmitted ultrasonic wave in the thickness direction of specimen, the maximum amplitude was measured when there was no specimen between the transmitting and receiving transducers. 2 transducers adhered together with silicone grease were utilized. The maximum amplitude of the receiving transducer was measured when the ultrasonic pulse with $200 \mathrm{kHz}$ frequency was output from the function synthesizer. The results are shown in Fig. 2. When the ultrasonic pulse was set within the range of conditions at 1.5, 2.0, 3.0, 4.0 and $5.0 \mathrm{~V}$, the maximum amplitude of the transmitted ultrasonic wave increased in proportion to the ultrasonic pulse voltage to $4.93,5.66,6.86,6.98$ and $7.44 \times 10^{-4} \mathrm{~V}$ respectively. It was suggested that each of the maximum amplitudes was a standard value for deciding the attenuation of the transmitted ultrasonic wave when each setup of the pulsed ultrasonic wave was transmitted through a specimen.

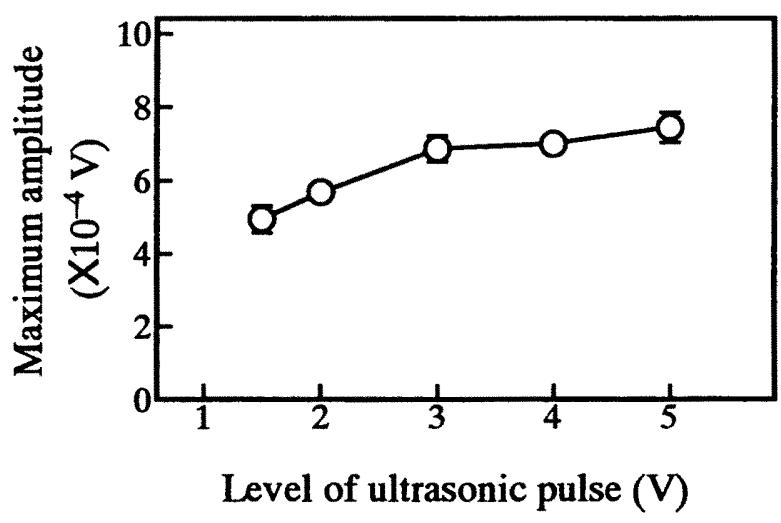

Fig. 2. Relationship between the level of ultrasonic pulse and maximum amplitude.

\section{Level of ultrasonic pulse}

To examine the influence of the level of ultrasonic pulse input to the PB specimen, ultrasonic pulse were set at $1.5,2.0,3.0,4.0$ and $5.0 \mathrm{~V}$ with a frequency of $200 \mathrm{kHz}$. Their transit time and maximum amplitude were then detected. The test specimen size used in this portion of the experiment was $100 \times 100 \times 20 \mathrm{~mm}$. The results shown in Fig. 3 indicated that the level of ultrasonic pulse insignificantly influenced the ultrasonic velocity. 

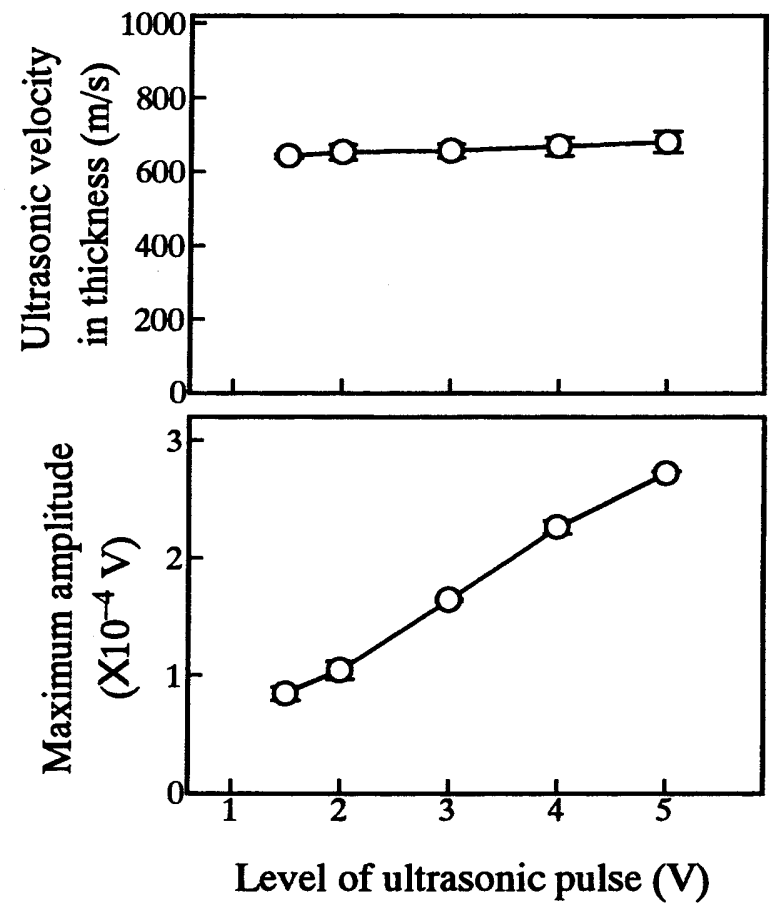

Fig. 3. Effect of the level of ultrasonic pulse on the ultrasonic velocity and maximum amplitude.

The ultrasonic velocity range was from 650 to $700 \mathrm{~m} / \mathrm{s}$. These values were similar to the ultrasonic velocity for $\mathrm{PB}$ in the thickness direction when the board density was from 0.60 to $0.70 \mathrm{~g} / \mathrm{cm}^{3}$ (Han Chien Lin et al., 2000 and Sun et al., 1999).

The maximum amplitude of the transmitted ultrasonic wave after passing through a PB specimen, $20 \mathrm{~mm}$ in thickness, showed a tendency to increase in a proportion to the level of the ultrasonic pulse. Based upon the amplitude detected without a specimen (Fig. 2), the proportion of the transmitted ultrasonic wave attenuation in the thickness direction at 4.0 and $5.0 \mathrm{~V}$ was about $70 \%$ followed by $3.0,2.0$ and $1.5 \mathrm{~V}$ about $76 \%, 82 \%$ and $84 \%$ in that order. The higher voltage of the ultrasonic pulse is generally more sensitive to the internal parts of $\mathrm{PB}$ for measuring the maximum amplitude. The maximum amplitude is a significant parameter to observe the attenuation of the transmitted ultrasonic wave. It is also considered that the multiple transform condition and the unification of analysis are required. The ultrasonic pulse set at $5 \mathrm{~V}$ was therefore selected to measure the transmit time and the maximum amplitude for the following experiment.

\section{Setting pattern}

Whether or not the setting pattern would influence the ultrasonic velocity and the maximum amplitude was observed. The setting pattern in this experiment was consid- 
ered as 4 types; a) place the specimen on a stand, b) fix the specimen with a vice, c) suspend the specimen with 2 threads and d) suspend the specimen with a thread through into a hole, shown at the bottom of Fig. 4. The ultrasonic pulse frequency was set at $200 \mathrm{kHz}$ as a constant factor. The amplitude of ultrasonic pulse was set at 1.5, 2.0, 3.0, 4.0 and $5.0 \mathrm{~V}$ respectively. The result, shown at the top of Fig. 4 , indicated that the setting pattern of the specimen did not influence the ultrasonic velocity significantly.

The maximum amplitude of the transmitted ultrasonic wave showed an increased tendency in a proportion to the level of ultrasonic pulse for each setting pattern. The maximum amplitude of the setting pattern d) was smaller than the others for each level of ultrasonic pulse. It is suggested that setting pattern d) is not suitable for detecting the maximum amplitude because the unstable condition influences to the vibration mode, and the maximum amplitude value was too small to obtain. The uniformity of setting pattern is necessary to the maximum amplitude measurement.

\section{Location of transducers (measuring position)}

Contact-type transmitting and receiving transducers were mounted on both surfaces of the specimen in opposite directions. But there is a possibility that the location of transducers on the board surfaces or the deviation (a little offset of position) of both transducers will influence on the measurement result.

The transducer locations were examined first. Transducers were mounted at different places on a PB specimen, $50 \times 50 \times 20 \mathrm{~mm}$ (the bottom of Fig. 5). The sensors were mounted at the intersection points of a line divided equally by 10 in the horizontal direction and in the vertical direction to produce 4 equal sections. The ultrasonic velocity and the maximum amplitude at each point of intersection were measured. The results are shown at the top of Fig. 5. The ultrasonic velocity was about the same in the horizontal direction. The measurement position differences in the vertical direction did not have any influence on the ultrasonic velocity as a result. However, the maximum amplitude changed greatly with the position in the horizontal direction. When the distance in the vertical direction from the bottom edge of the specimen to the transducers was $25.0 \mathrm{~mm}$ on the central line, or $37.5 \mathrm{~mm}$ on the upper line, the maximum amplitude showed about the same tendency in the horizontal direction which was a little lower in the central part of the horizontal direction and larger to both ends. Comparing to the distance from the bottom edge of the specimen $(12.5 \mathrm{~mm})$ on the lower line, the maximum amplitude was larger at the center of the specimen and became smaller at both ends. Moreover, the center portion of the specimen in the horizontal direction showed a smaller difference in the maximum amplitude compared to both ends. It was decided to mount as accurately as possible in the center of the specimen for the AU transmission examination in the thickness direction.

An AU transmission experiment using a slender specimen with a length of $100 \mathrm{~mm}$ and a width of $20 \mathrm{~mm}$, shown at the bottom of Fig. 6, was conducted. The sensors were mounted $10 \mathrm{~mm}$ apart from one side to the other edge. The specimen was placed either in a vertical or horizontal position. Results indicated that the ultrasonic velocity showed an approximate equal value in whichever direction the specimen was placed and wherever the sensors were mounted. The maximum amplitude was low when the sensors were mounted at both ends and the center of specimen. The maximum amplitude was 


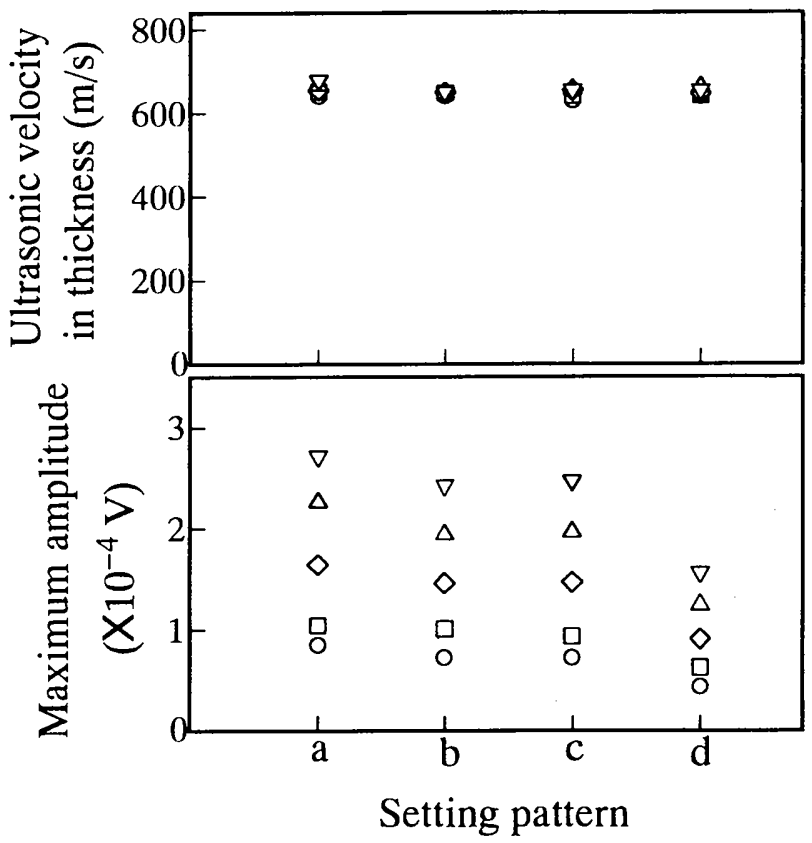

Fig. 4. Effect of setting pattern on the ultrasonic velocity and maximum amplitude for particleboard specimen.

Symbols: The level of ultrasonic pulse $(\mathrm{V}) ; \bigcirc 1.5, \square 2.0, \diamond 3.0$, $\triangle 4.0, \nabla 5.0$.

Notes: Setting pattern:

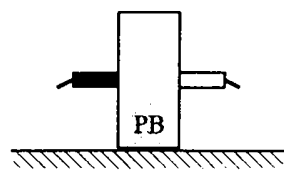

a Place on a stand

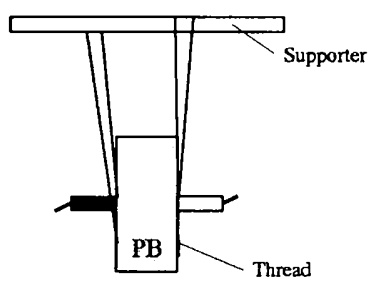

c) Suspend with 2 threads

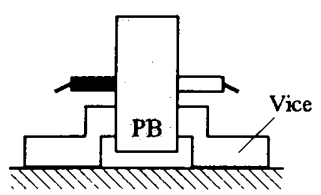

b ) Fix with a vice

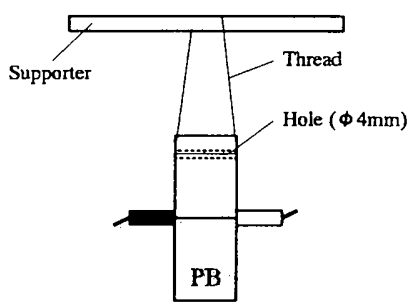

d) Suspend with a thread through a hole

: Receiving transducer, $\square$ : Transmitting transducer. 


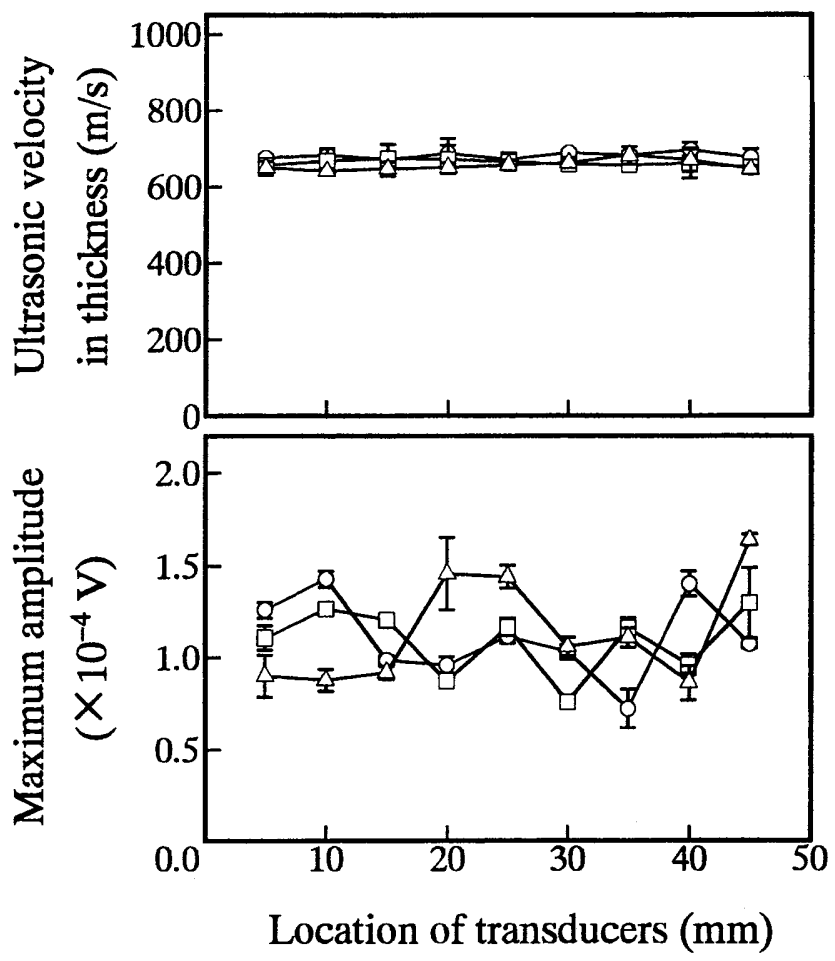

Fig. 5. Effect of the transducer locations on the ultrasonic velocity and maximum amplitude.

Symbols: $\bigcirc$ Upper line $(37.5 \mathrm{~mm}), \square$ Central line $(25 \mathrm{~mm})$, $\triangle$ Lower line $(12.5 \mathrm{~mm})$.

Notes: Location of transducers:

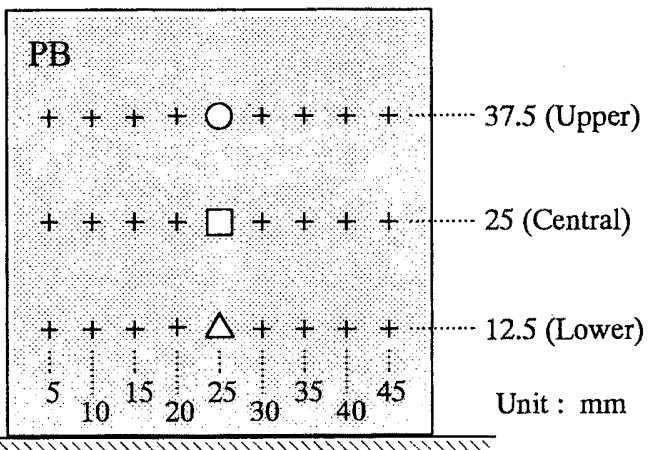

Board size : $50 * 50 * 20 \mathrm{~mm}$

$\bigcirc, \square, \triangle,+$ : Setting place for each of transducer 

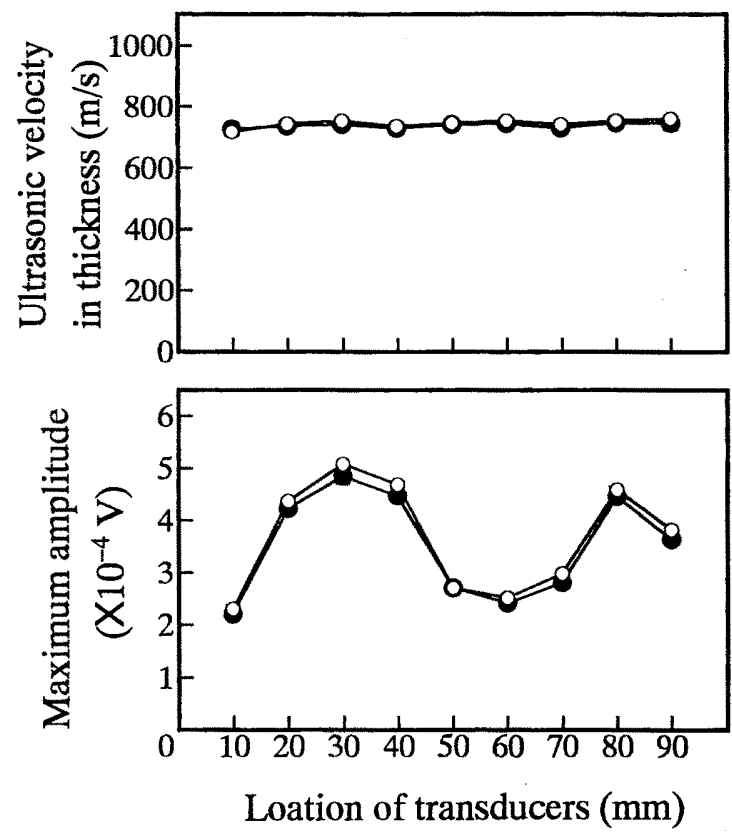

Fig. 6. Effect of the transducer locations, and placing mode on the ultrasonic velocity and maximum amplitude.

Symbols: Placing in vertical, $\bigcirc$ Placing in horizontal.

Notes: Location of transducers and placing mode for rectangle specimen:

Placing in vertical :

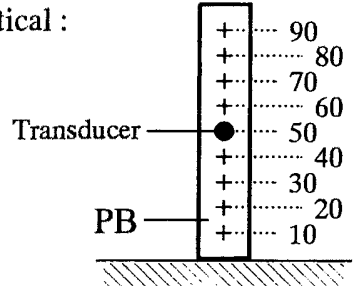

Placing in horizonal :

$$
\text { Unit: mm }
$$

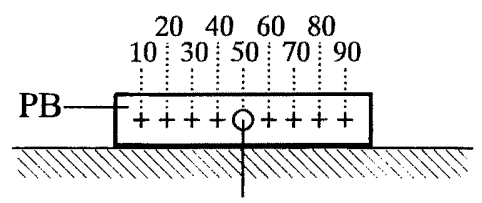

Transducer 

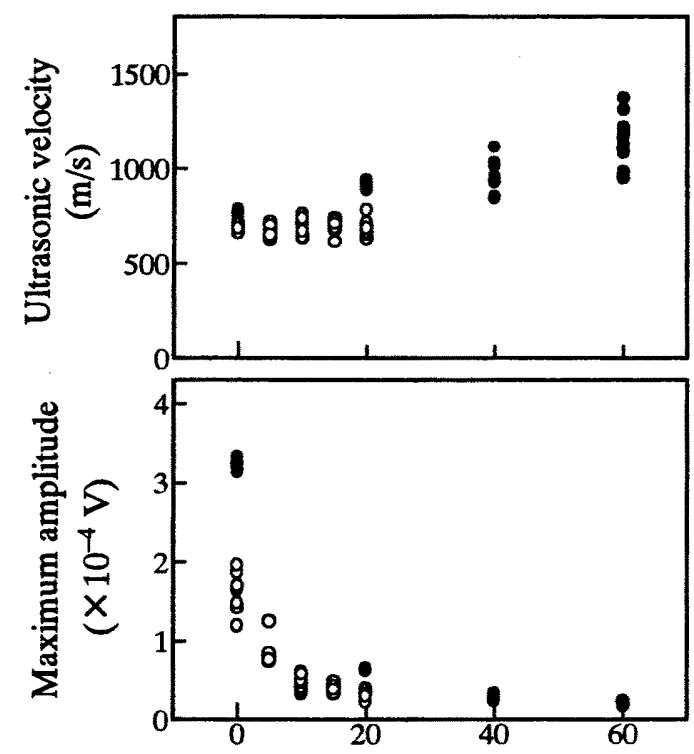

Horizontal distance between 2 transducers ( $\mathrm{mm}$ )

Fig. 7. Effect of the horizontal destance between 2 transducers on the ultrasonic velocity and maximum amplitude.

Symbols: $\bigcirc$ Board size $50 * 50 * 20 \mathrm{~mm}$,

- Board size $100 * 100 * 20 \mathrm{~mm}$.

Notes: Mounting position of 2 tranducers on horizontal distance in thickness direction of specimen:

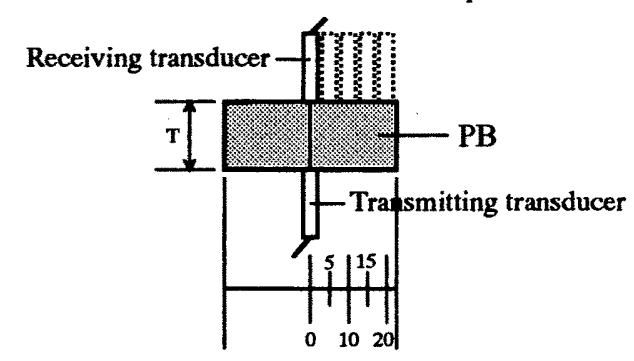

Board size : $50^{*} 50^{*} 20 \mathrm{~mm}$

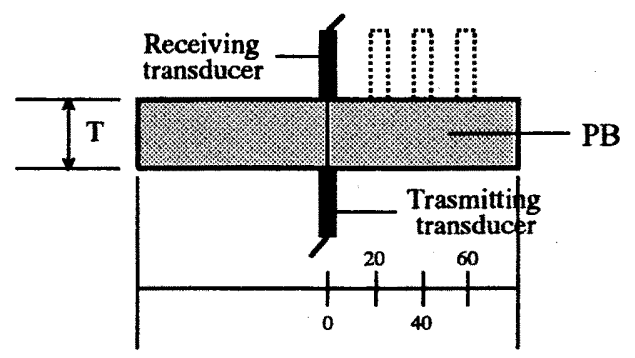

Board size : $100^{*} 100 * 20 \mathrm{~mm}$

$T$ : Thickness of specimen 
high when sensors were placed in the middle of those points. The influence of the specimen placement in the vertical or horizontal position on the maximum amplitude showed no difference. In accordance with the placement mode and the transducer locations, the difference in the ultrasonic velocity results was insignificant. The setting pattern and the mounted position of the sensors did not require careful treatment for the ultrasonic velocity measurement. The maximum amplitude measurement confirmed that the mounted position of the sensors was important in the AU transmission measurement.

Finally, the influence of the deviation in the sensors mounted on the opposite sides of the specimen for the ultrasonic velocity and maximum amplitude measurement was examined in this part of experiment. The transmitting transducer was mounted at the center of a specimen $50 \times 50 \mathrm{~mm}$ or $100 \times 100 \mathrm{~mm}$. The receiving transducer was mounted individually from the center to the diagonal line at a point $5 \mathrm{~mm}$ and $20 \mathrm{~mm}$ apart for a specimen size of 50 and $100 \mathrm{~mm}$ square, respectively (the bottom of Fig. 7). The ultrasonic velocity and the maximum amplitude were measured. Results indicated the ultrasonic velocity was about 600 to $700 \mathrm{~m} / \mathrm{s}$ that did not change in the range of a horizontal distance from 0 to $20 \mathrm{~mm}$ for a specimen size of $50 \times 50 \mathrm{~mm}$. The dispersion of ultrasonic velocity was very small when the horizontal distance between 2 transducers was $0 \mathrm{~mm}$ in comparison with the others. The ultrasonic velocity showed a tendency to become faster with the increase in the distance in the horizontal direction between both sensors, when the horizontal distance was larger than $20 \mathrm{~mm}$. In general, the ultrasonic velocity in the longitudinal (fiber) direction of wood was faster than that at a right angle to the fiber direction (Mishiro, 1996). It is thought that the particles were flattened in the horizontal direction during the manufacturing process. The flattened particles were similar in the longitudinal direction of wood so that the ultrasonic velocity was faster (Sumire, 1994 and Sun et al., 1999). It is suggested that the ultrasonic wave transmission in the longitudinal direction of particles became higher as the horizontal distance between the sensors became greater because the longitudinal direction of the particles were arranged in the board surface direction. Therefore, it is thought that the ultrasonic velocity became faster as the horizontal distance became greater. The maximum amplitude, on the other hand, was influenced significantly by the horizontal distance and showed a tendency to become smaller as the horizontal distance between both sensors became greater. It is suggested that a small transducer offset will influence the maximum amplitude measurement because the maximum amplitude decreases drastically in the range of $20 \mathrm{~mm}$. It is necessary to pay more attention to the distance of the sensors in the horizontal direction when the maximum amplitude is measured.

\section{Board size}

Because the $100 \times 100 \mathrm{~mm}$ specimen showed larger maximum amplitude than the $50 \times 50 \mathrm{~mm}$ specimen in Fig. 7 , the influence of the specimen dimension was examined in detail of the change patterns. Two patterns of board dimensions were considered in this experiment. One specimen pattern was fixed in length and the width was changed, as shown at the bottom of Fig. 8. The other specimen pattern was changed in both length and width (a square size).

Results, shown at the top of Fig. 8 , indicated that the difference in the specimen width from $20 \mathrm{~mm}$ to $100 \mathrm{~mm}$ did not influence the ultrasonic velocity. The maximum 
amplitude did vary as the width of specimen was changed. Moreover, the results shown in Fig. 9 indicated that the influence of the length on the ultrasonic velocity and maximum amplitude was the same as the case in the Fig. 8. The maximum amplitude showed a tendency to become larger as the length of one side became greater. Considering the case in both Fig. 8 and Fig. 9, the ultrasonic velocity was not influenced
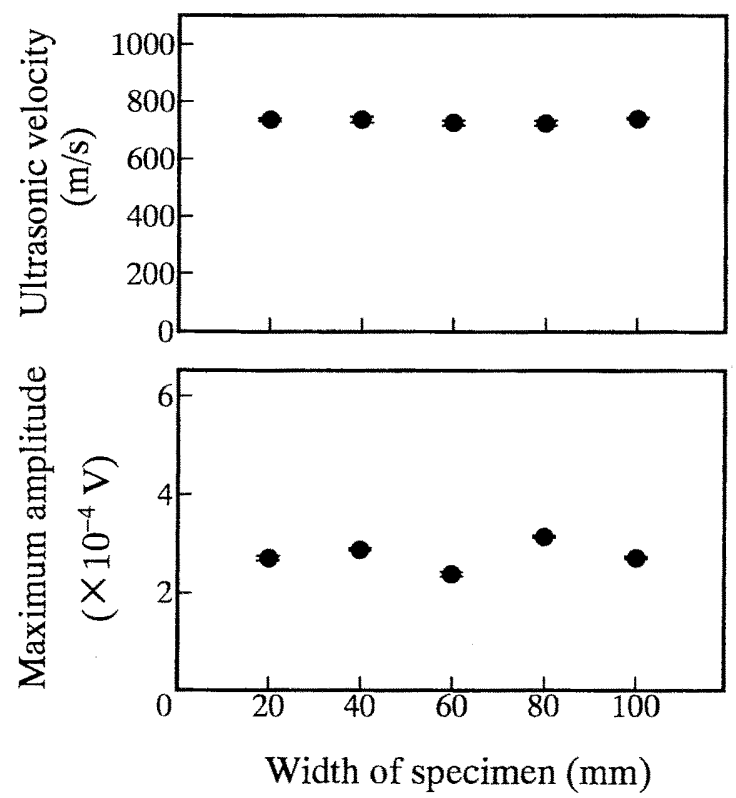

Fig. 8. Effect of specimen width on the ultrasonic velocity and maximum amplitude.

Notes: The width change of specimen

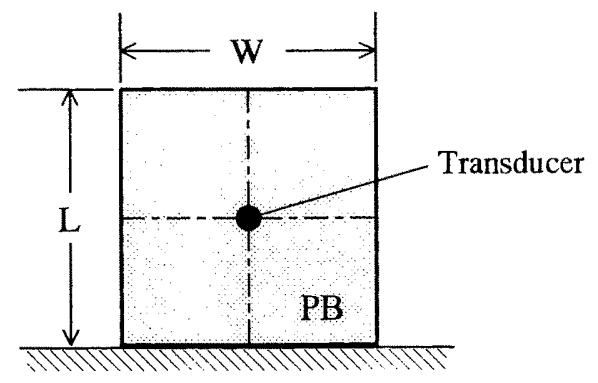

Variable factor: W 20,40,60, 80, $100(\mathrm{~mm})$

Constant factor: L $100(\mathrm{~mm})$, T $20(\mathrm{~mm})$ 


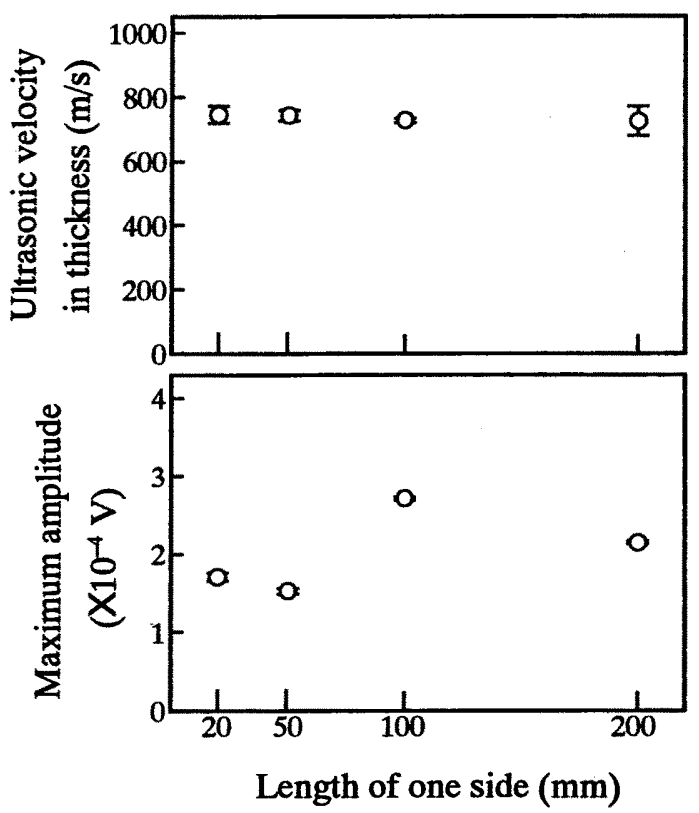

Fig. 9. Effect of square specimen size on the ultrasonic velocity and maximum amplitude.

by the change in board size. But it is necessary to pay an attention in the examination of maximum amplitude.

\section{Fixing pressure}

Generally speaking, the difference of pressure influenced the received signal. An exclusive sensor holder was used in the $\mathrm{AE}$ measurement in order to fix the sensor onto the specimen at the same fixing pressure (Miller R K and Mclintire P 1978). The influences of the fixing pressure on the velocity and maximum amplitude of the transmitted ultrasonic wave and the optimum pressure to fix the sensor were examined. This experiment included a case in which no specimen was placed between the sensors. The fixing pressure of the sensors was changed optionally from 0.05 to $0.5 \mathrm{kgf} / \mathrm{cm}^{2}$. An additional case involved a commercial PB of thickness $20 \mathrm{~mm}$ placed between the two sensors. The fixing pressure was changed within the range from 0.35 to $0.5 \mathrm{kgf} / \mathrm{cm}^{2}$ because of the limit of the spacer size to obtain a good fixed condition (Fig. 12). The spiral spring was used to fix the sensor at a stable pressure in the built-in holder. The pressure of the sensors was calculated by the deformation of the spiral spring and the contact area between the sensor and the specimen.

The fixing pressure showed that there was almost no change under $0.4 \mathrm{kgf} / \mathrm{cm}^{2}$ when there was no specimen between both sensors, but it seemed to show a tendency to become larger when it exceeded $0.4 \mathrm{kgf} / \mathrm{cm}^{2}$, as shown in Fig. 10 . As the fixing pressure 


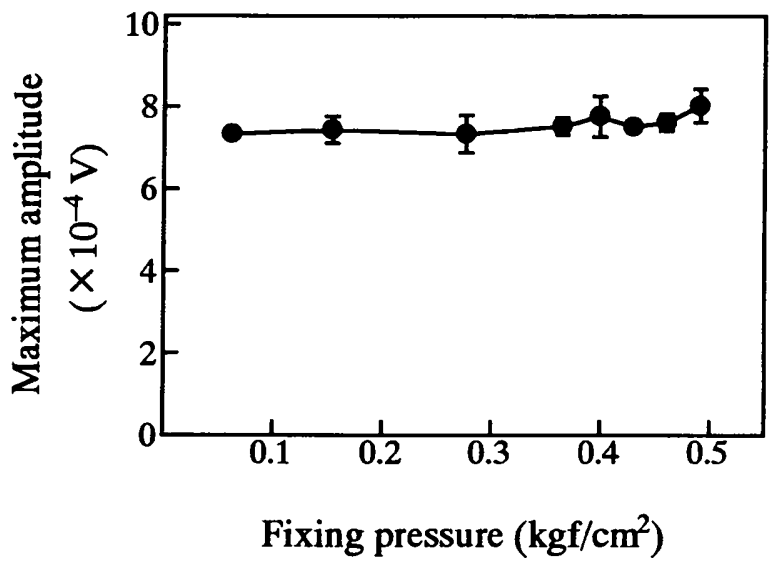

Fig. 10. Effect of fixing pressure with spring on maximum amplitude when there was no specimen between both transducers.
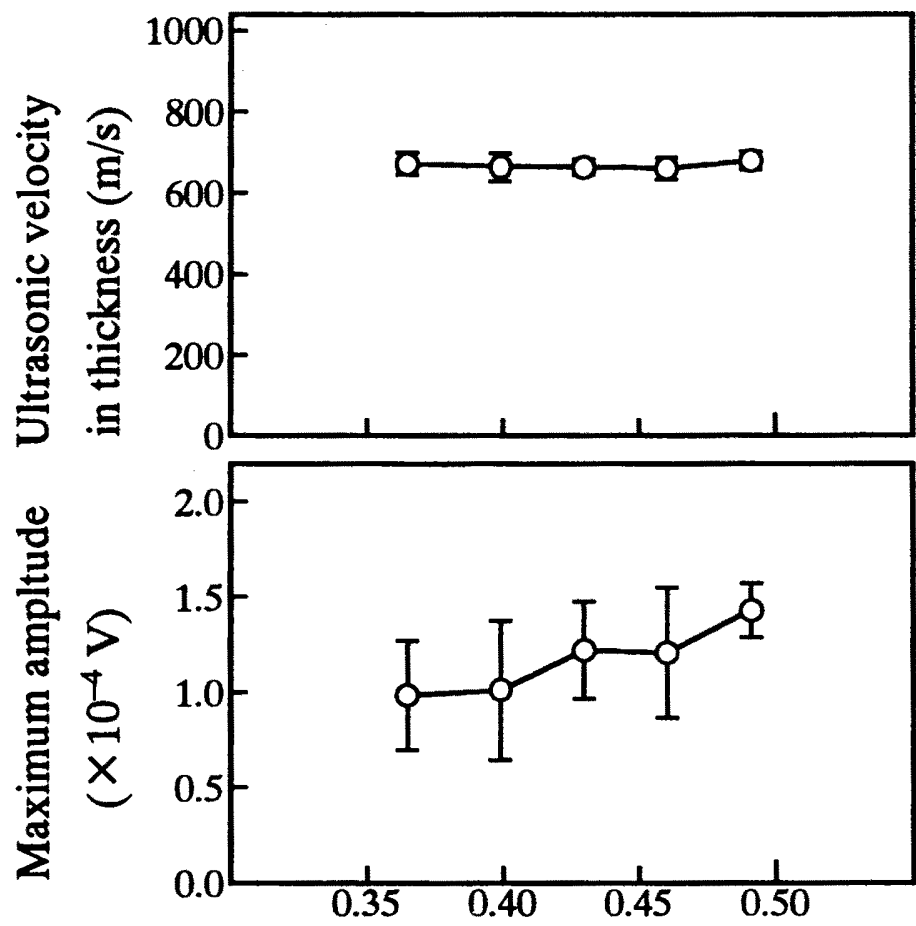

Fixing pressure $\left(\mathrm{kgf} / \mathrm{cm}^{2}\right)$

Fig. 11. Effect of fixing pressure with spring on the ultrasonic velocity and maximum amplitude for particleboard specimen. 
of the sensors became larger, the maximum amplitude showed a tendency to increase when there was a specimen between both sensors, as shown in the Fig. 11. The influence of the fixing pressure when both sensors were fixed without a specimen was not found because the contact area between sensors was very smooth. The maximum amplitude was influenced when there was a specimen between the sensors because the surface of the $\mathrm{PB}$ specimen was not smooth. The fixing pressure was not enough to make the sensor contact with the surface of specimen entirely even though both of sensors were mounted on each surface of specimen using silicone grease. As a result, the difference in the maximum amplitude depended upon the contact condition of the specimen and the sensor. As the fixing pressure became greater, the degree of change in the maximum amplitude became larger. It is suggested that the fixing pressure must be set as uniformly as possible for the examination of maximum amplitude.

\section{Auxiliary apparatus (a built-in holder with a vice)}

From the above experimental results, it was confirmed that both transmitting and receiving transducers must be set accurately in the horizontal direction and the fixing pressure of the sensors must be constant.

In order to solve these problems and obtain a stable and accurate measurement value, an auxiliary apparatus, that is, the built-in holders with a vice for the sensors and the specimen was designed. The illustration is shown in Fig. 12. The transmitting and receiving transducers were individually set in each side of the built-in holder and a uniformed pressure could be obtained. Both side of the built-in holders were fixed onto a vice in order to locate both sensors on the center of the specimen in the horizontal direction at the opposite side. The built-in holder also could be moved without a deviation in the centerline of the sensors. The sensors were fixed uniformly on the specimen by adjusting the distance of the built-in holder. Silicone grease was used to produce the sensor contact with the surface of specimen entirely. According to the size and thickness of specimen, the AU transmission measurement in the center of the specimen could always be conducted easily because of the dimensions of the spacer.

A precise installation of the sensors to the specimen was achieved easily using this auxiliary apparatus. The auxiliary apparatus enable to obtain an accurate and stable

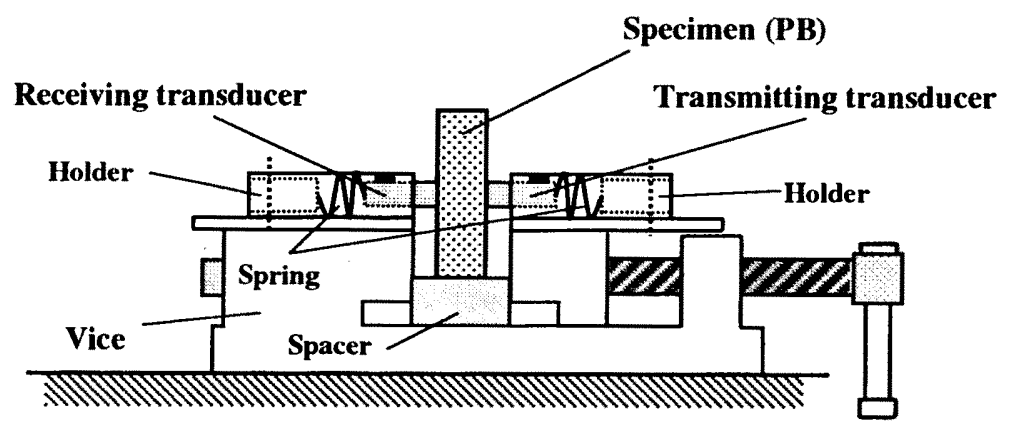

Fig. 12. Illustration of auxiliary apparatus, the built-in holders on a vice. 
measurement value for the maximum amplitude by insuring a secure adjustment of the uniformed pressure of the sensor to the specimen.

\section{REFERENCES}

Akiyoshi Mishiro 1996 Effect of density on ultrasonic velocity in wood. Mokuzai Gakkaishi, 42(9): $887-894$

Han Chien Lin, Y. Fujimoto, and Y. Murase 2000 Influence of internal structural factor on ultrasonic wave transmission characteristic of particleboard. Abstracts of The 50th Annual meeting of The Japan Wood Research Society, 50: 279

Miller R. K. and Mclintire P. 1978 Nondestructive testing handbook. Acoustic emission testing second edition volume five. American Society for Nondestructive Testing, Ohio (English), pp 11-22, 34-38, $45-62$

Sumire Kawamoto 1994 Attenuation of ultrasonic waves in wood. Mokuzai Gakkaishi, 40(7): 772-776

Sun, Y. G. and Arima T. 1999 Structural mechanics of wood composite materials I: ultrasonic evaluation of internal bond strength during an accelerated aging test. J. Wood Sci., 44: 348-353

Sun, Y. G. and Arima T. 1999 Structural mechanics of wood composite materials II: ultrasonic propagation mechanism and internal bonding of particleboard, J. Wood Sci., 45: 221-226

Y. Fujimoto, Han Chien Lin, and Y. Mataki 1997 Behavior of acoustic emission generation during tensile test perpendicular to the plane of particleboard -Particularly, effect of internal structural factor of board -. J. Soc. Mat. Sci., Japan, 46(4): 413-418 